\title{
Gestão para a Sustentabilidade em Empresas do Setor Mineral
}

\section{Management for Sustainability in the Mineral Sector Enterprises}

\section{Jordana Marques Kneipp}

Doutoranda do Programa de Pós-Graduação em Administração, Universidade Federal de Santa Maria - Santa Maria - RS, Brasil.

E-mail: jordanakneipp@yahoo.com.br

\section{Clandia Maffini Gomes}

Professora do Departamento de Ciências Administrativas, Universidade Federal de Santa Maria - Santa Maria - RS, Brasil. E-mail: clandia@smail.com.br

\section{Roberto Schoproni Bichueti}

Mestrando do Programa de Pós-Graduação em Administração, Universidade Federal de Santa Maria - Santa Maria - RS, Brasil. E-mail: robertobichueti@hotmail.com

\section{Emerson Antonio Maccari}

Professor do Programa de Pós-Graduação em Administração, Universidade Nove de Julho - São Paulo - SP, Brasil. E-mail: emersonmaccari@gmail.com

\section{Resumo}

Cada vez mais, a competitividade das empresas está relacionada a uma gestão orientada para a sustentabilidade, que integre a preservação ambiental, o bem-estar social e a prosperidade econômica. O estudo teve como objetivo analisar a adoção de práticas de gestão para a sustentabilidade em empresas do setor mineral sob a perspectiva da teoria institucional. A pesquisa caracteriza-se como qualitativa $e$ foi desenvolvida por meio de entrevistas exploratórias com três empresas do setor mineral. Os resultados permitiram concluir que, nas empresas analisadas, a integração da sustentabilidade com a estratégia ainda se trata de uma preocupação recente e orientada primordialmente para o atendimento das exigências legais. Evidenciou-se um maior direcionamento das empresas analisadas no que se refere à adoção de práticas de gestão social. As práticas de gestão ambiental buscam basicamente atender aos requisitos legais e às exigências mercadológicas.

Palavras-chave: Gestão. Sustentabilidade. Indústria Mineral.

\section{Abstract}

Business competitiveness is increasingly linked to a management oriented to sustainability. The study aimed to analyze the adoption of management practices for sustainability in the mining sector companies from the perspective of institutional theory. The research is characterized as qualitative and was developed through exploratory interviews with three companies in the mining sector. The results showed that, in the analyzed companies, the integration of sustainability with the strategy it is still a concern recently and oriented primarily to meet the legal requirements. Thus indicating a greater targeting of companies analyzed in relation to the adoption of social management practices. The environmental management practices seek to basically meet the legal requirements and marketing requirements.

Key words: Management. Sustainability. Mining Industry. 


\section{INTRODUÇÃo}

O desenvolvimento econômico e tecnológico traz reflexos para a sociedade e para o meio ambiente, criando novas exigências e condicionantes para a atividade industrial. Cada vez mais, a competitividade das empresas está relacionada a uma gestão orientada para a sustentabilidade, que integre a preservação ambiental, o bem-estar social e a prosperidade econômica.

A empresa comprometida com o futuro e com a sustentabilidade é aquela que possui um modelo de negócios que avalia as consequências e os impactos de suas ações e contempla aspectos sociais e ambientais na sua visão financeira. (ALIGLERI; ALIGLERI; KRUGLIANSKAS, 2009)

A gestão empresarial comprometida com a sustentabilidade representa uma questão importante em todos os segmentos econômicos e empresariais, entretanto alguns setores possuem desafios maiores, tendo em vista a sua natureza produtiva.

A indústria mineral, objeto deste estudo, enfrenta alguns dos desafios mais difíceis de todo o setor industrial, em se tratando de desenvolvimento sustentável. Os minerais são essenciais para a vida cotidiana, pois se transformam em numerosos produtos utilizados pela população e constituem matérias-primas essenciais em um grande número de indústrias. Por outro lado, a extração e o processamento de minerais estão associados a uma série de impactos socioambientais, que precisam ser gerenciados a fim de que o setor desenvolva-se de forma sustentável. (AZAPAGIC, 2004)

No Brasil, o setor mineral desempenha um papel importante no âmbito nacional e internacional, tendo significativa relevância na economia do país. Para Sabedot (2005), a atividade mineradora brasileira representa um dos pilares da economia brasileira $e$ destaca-se no panorama internacional, em função das expressivas reservas, da produção, da comercialização $e$ da exportação de diversos minerais.

Desse modo, em função da representatividade econômica da indústria mineral brasileira e dos desafios inerentes à gestão para a mineração sustentável, este estudo possui como objetivo analisar a adoção de práticas de gestão para a sustentabilidade em empresas do setor mineral sob a perspectiva da teoria institucional.

\section{Gestão para a Sustentabilidade}

A relação entre o desenvolvimento dos negóciose o desenvolvimento sustentável representa uma questão relativamente nova, introduzida na década de 1980, mudando definitivamente o relacionamento entre a empresa e o meio ambiente. A análise do pensamento dos ecologistas e dos economistas, em relação ao tema, leva ao entendimento de que as teorias econômicas convencionais não podem guiar o futuro uma vez que nunca consideraram o impacto do capital natural. As indústrias se beneficiaram historicamente do capital natural, destruindo-o, e o sistema industrial do presente se baseia em princípios de contabilidade arcaicos. (PARK, 2008)

Barbieri et al. (2010) afirma que a adesão das empresas ao movimento pelo desenvolvimento sustentável ocorreu inicialmente em virtude de pressões externas, como resposta às críticas e às objeções das entidades governamentais e da sociedade civil organizada que responsabilizavam as empresas pelos processos de degradação social e ambiental que atingiam o planeta, além disso, recentemente representa fator de competitividade empresarial, podendo ser fonte de diferenciação ou de qualificação para continuar no mercado.

As organizações sustentáveis são aquelas que buscam ser economicamente viáveis e competitivas no mercado, produzindo de maneira que não agrida o meio ambiente e contribuindo para o desenvolvimento social da região e do país em que atuam (ALMEIDA, 2002). Ainda, segundo Savitz (2007, p. 2), a “[...] empresa sustentável é aquela que gera lucro para os acionistas, ao mesmo tempo em que protege o meio ambiente e melhora a vida das pessoas com quem mantém interações".

Com base no conceito de organização sustentável, o desafio consiste em unir o bem-estar econômico, a equidade social $e$ a proteção ao meio ambiente a partir de ações de longo prazo. A integração entre as dimensões econômica, social e ambiental resulta em um novo paradigma produtivo, sob a perspectiva do desenvolvimento sustentável, enfatizando a sustentabilidade dos processos e dos produtos, possibilitando uma melhor qualidade de vida ao homem a partir de seu meio. (DAROIT; NASCIMENTO, 2004)

As dimensões da sustentabilidade estão intrínsecas no conceito de empresa sustentável e são 
representadas a partir do Triple Bottom Line, que se tornou conhecido no âmbito empresarial a partir da publicação do livro Cannibals with Forks: The Triple Bottom Line of 21st-Century Business, em 1997. O conceito de Triple Bottom Line é apresentado por Elkington (2001) por meio de uma metáfora de um garfo composto por três dentes, sendo que cada dente refere-se às dimensões econômica, social e ambiental da sustentabilidade em termos de resultados líquidos, procurando responder à pergunta: o capitalismo, assim como um canibal, se tornaria civilizado se usasse garfo?

As três dimensões da sustentabilidade, comumente denominadas como tripé da sustentabilidade, devem estar integradas, de modo que, na esfera ambiental, os recursos naturais sejam utilizados de forma a não prejudicar as gerações futuras, reduzindo os impactos da ação das indústrias. Na perspectiva econômica, faz-se necessária a preservação da lucratividade da empresa $e$ o não comprometimento do seu desenvolvimento econômico. E por fim, na esfera social, que inclui a questão da justiça social, o objetivo maior é o desenvolvimento de um mundo mais justo, através das relações com todos os stakeholders. (ELKINGTON, 2001)

A gestão para a sustentabilidade com base nas dimensões econômica, social e ambiental possui como premissa possibilitar ganhos para a empresa, sociedade e meio ambiente. Aligleri (2011, p. 24) define a gestão sustentável como

[...] uma abordagem de negócios que considera o padrão de organização dos ecossistemas nos processos de decisão e nas práticas de gestão contemplando indicadores de avaliação nas dimensões econômica, ambiental e social.

A gestão empresarial comprometida com a sustentabilidade representa uma questão importante em todos os segmentos econômicos e empresariais, entretanto alguns setores possuem desafios maiores, tendo em vista a sua natureza produtiva.

\subsection{Gestão para a Sustentabilidade na Indústria Mineral}

A indústria mineral enfrenta alguns dos desafios mais difíceis de todo o setor industrial, em se tratando de desenvolvimento sustentável. Os minerais são essenciais para a vida cotidiana, pois se transformam em numerosos produtos utilizados pela população $e$ constituem matérias-primas essenciais em um grande número de indústrias. Por outro lado, a extração e o processamento de minerais estão associados a uma série de impactos socioambientais, que precisam ser gerenciados a fim de que o setor desenvolva-se de forma sustentável. (AZAPAGIC, 2004)

$\mathrm{Na}$ indústria mineral, a incorporação de práticas de gestão para a sustentabilidade visa minimizar os impactos ambientais inerentes a esta atividade produtiva. Para Hilson e Murck (2000), o desenvolvimento sustentável no setor de mineração requer um compromisso de melhoria contínua ambiental e socioeconômica, nas fases de exploração, operação e encerramento das atividades.

Além dos instrumentos legais, há também mecanismos indutores de mercado que têm contribuído favoravelmente para que as grandes companhias mineradoras assumam maior compromisso com o desenvolvimento sustentável, como ações das companhias mineradoras em bolsas de valores, instrumentos voluntários e de comunicação como a adesão aos programas e certificações ambientais. (ENRÍQUEZ; DRUMMOND, 2007; ENRÍQUEZ, 2009)

Para Viana (2007), a consolidação de uma política ambiental é imprescindível para a adoção de normas internacionais, como a da série International Organizations for Standardization (ISO) 14001, que envolve diretrizes para o sistema de gestão ambiental, avaliação e certificação de qualidade ambiental $e$ critérios para avaliação da qualidade e eficácia das relações empresa/ambiente.

A preocupação ambiental das empresas do setor mineral não envolve somente a preservação de um ecossistema e a garantia de segurança da comunidade, considera também o bem-estar humano e os direitos dos habitantes locais, a qualidade de vida das atuais e futuras gerações. Os princípios de desenvolvimento sustentável demandam o crescimento econômico e a preservação ambiental desde o início de um projeto, incluindo a avaliação dos valores morais e éticos, considerando valores subjetivos da comunidade, ao invés de apenas enfatizar o tradicional valor econômico. (AMADE; LIMA, 2009)

Enríquez (2009) constatou que grandes municípios mineradores brasileiros possuem um forte sistema de proteção ambiental, em virtude de que a dimensão 
ambiental está razoavelmente institucionalizada em torno de marcos regulatórios e de órgãos ambientais. $\mathrm{O}$ autor constatou também que as minas mais recentes apresentam postura proativa ambiental, ao contrário das minas antigas. Outro aspecto evidenciado é que, apesar dos marcos legais brasileiros, o direcionamento ao mercado exportador parece ser um fator de pressão muito mais efetivo para uma mineração menos agressiva ambientalmente.

Solomon, Katz e Lovel (2008), em estudo sobre o desenvolvimento sustentável na indústria mineral da Austrália, constataram que a questão social é bastante ampla e complexa, e precisa ir além da ideia de "comunidade", sendo necessária uma mudança cultural para que as todas as perspectivas sociais sejam integradas e consideradas.

Considerando-se as peculiaridades do setor e a importância do seu envolvimento e compromisso com a sustentabilidade, são expressivos os movimentos em prol do desenvolvimento sustentável na indústria mineral. Esses movimentos impulsionam a mineração na obtenção da sua licença social para operar, a partir da integração da sustentabilidade em suas estratégias.

Para Azapagic (2004), algumas iniciativas internacionais são importantes no que se refere ao desenvolvimento sustentável na indústria mineral, como a norte-americana United States Sustainable Minerals Roundtable, a canadense Canadian Minerals and Metals Initiative e a europeia European Industrial Minerals Association. Outra iniciativa que merece destaque consiste na criação do Conselho Internacional de Mineração e Metais, denominado International Council on Mining and Metals (ICMM), que consiste em um fórum sediado em Londres, fundado em outubro de 2001, para representar as principais empresas internacionais de mineração e metais, com o objetivo de aprimorar a atuação das companhias do setor. (INTERNATIONAL COUNCIL ON MINING AND METALS, 2010)

Para atingir seu objetivo, o ICMM desenvolve parcerias com diversas instituições, como Organizações Não Governamentais (ONGs), Organismos Internacionais, Universidades, entre outras. Por meio dessas parcerias, o ICMM atua em várias questões, como a mudança climática, a saúde e a segurança das comunidades, o impacto da mineração na biodiversidade, os direitos dos povos indígenas e também os reflexos na indústria $e$ as consequências futuras do surgimen- to de novos agentes globais. A proposta consiste em estimular as mineradoras a aprender como é possível compartilhar práticas positivas. (INTERNATIONAL COUNCIL ON MINING AND METALS, 2010)

Segundo o International Council on Mining and Metals (2010), o Conselho desenvolveu, em 2003, um modelo para o desenvolvimento sustentável, denominado Sustainable Development Framework, a fim de assegurar uma padronização entre seus integrantes por meio da adoção e do cumprimento das políticas estipuladas pelo modelo. O framework é composto por dez princípios, relatórios públicos e auditoria independente, estando entre as mais avançadas iniciativas voluntárias em sua categoria, de forma a contribuir para melhorar a performance da indústria de mineração. Para o International Council on Mining and Metals (2010), a adoção do instrumento representa o compromisso da companhia mineradora com as boas práticas internacionais do setor.

Os dez princípios foram elaborados com base em outros padrões globais orientadores como a Declaração do Rio 1992, a Global Reporting Initiative, as Diretrizes da Organização para Cooperação e Desenvolvimento Econômico (OCDE) para empresas multinacionais, as políticas operacionais do Banco Mundial, a Convenção da OCDE sobre o combate à corrupção, as Convenções da Organização Internacional do Trabalho (OIT) 98, 169, 176 e os princípios voluntários sobre direitos humanos e segurança. (INTERNATIONAL COUNCIL ON MINING AND METALS, 2008)

O Quadro 1 apresenta os dez princípios estabelecidos pelo ICMM.

\section{Princípios do Desenvolvimento Sustentável}

1. Implementar e manter práticas comerciais éticas e sistemas íntegros de governança corporativa.

2. Integrar as considerações sobre o desenvolvimento sustentável ao processo de tomada de decisões corporativas.

3. Defender os direitos humanos fundamentais e respeitar a cultura, os costumes e os valores dos funcionários e de outras pessoas afetadas pelas atividades da empresa.

4. Implementar estratégias de gestão de riscos baseadas em dados válidos e na ciência bem fundamentada.

5. Buscar a melhoria contínua de nossa atuação nas áreas de saúde e segurança. 


\section{Princípios do Desenvolvimento Sustentável}

6. Buscar a melhoria contínua de nossa atuação na área ambiental.

7. Contribuir para a conservação da biodiversidade e das abordagens integradas ao planejamento do uso da terra.

8. Facilitar e incentivar o desenvolvimento, a utilização, a reutilização, a reciclagem e o descarte de nossos produtos de maneira responsável.

9. Contribuir para o desenvolvimento social, econômico e institucional das comunidades do entorno.

10. Estabelecer acordos efetivos e

transparentes com as partes interessadas

para o comprometimento, a comunicação e a

verificação independente das informações.

Quadro 1: Dez princípios para o desenvolvimento sustentável

Fonte: International Council on Mining and Metals (2008)

A fim de entender os fatores que levam as empresas a adotarem uma gestão para a sustentabilidade, a próxima seção discorre sobre a teoria institucional, como suporte teórico para a discussão sobre a busca pela legitimação por parte das organizações e a sua relação com a sustentabilidade empresarial.

\section{A Teoria Institucional e a Relação com a Sustentabilidade EMpresarial}

A teoria institucional vem sendo amplamente estudada nos mais diversos campos de estudo, tendo em vista que serve de base para o entendimento de diferentes fenômenos sociais. No âmbito da sustentabilidade empresarial, a teoria institucional pode servir de base para explicar o comportamento das empresas no que se refere à adoção de uma gestão para a sustentabilidade. Corroborando, Barbieri et al. (2010) defendem que a teoria institucional pode explicar o fato da institucionalização do conceito de desenvolvimento sustentável no âmbito empresarial, tendo em vista a abrangência espacial e a rápida popularização desse conceito nesse meio.

Segundo Carvalho, Vieira e Goulart (2005), a abordagem institucional sob os adjetivos de velho ou de novo institucionalismo oferece subsídios para o entendimento de fenômenos sociais em seus respecti- vos âmbitos do conhecimento, podendo ser explorada basicamente a partir de três vertentes: a política, a econômica e a sociológica. Uma breve contextualização das vertentes da teoria institucional é apresentada no Quadro 2.

\begin{tabular}{|l|l|}
\hline VERTENTE & \multicolumn{1}{c}{ PERSPECTIVA HISTóRICA } \\
\hline Política & $\begin{array}{l}\text { Em fins do século XIX Apresenta estruturas } \\
\text { legais e formas particulares de governança, } \\
\text { enquanto estudos da década de } 1970 \\
\text { trazem à tona questóes como a autonomia } \\
\text { das instituições políticas a partir de pressões } \\
\text { sociais e políticas institucionais promotoras } \\
\text { de cooperação internacional. }\end{array}$ \\
\hline \multirow{5}{*}{ Econômica } & $\begin{array}{l}\text { Introduz em sua origem a estrutura } \\
\text { social como determinante de processos } \\
\text { econômicos; e, na década de } 1970, \\
\text { direciona-se para análises microprocessuais } \\
\text { e predominantemente endógenas. }\end{array}$ \\
\hline \multirow{5}{*}{ Sociológica } & $\begin{array}{l}\text { Inicialmente, apresenta as relações entre } \\
\text { organização e ambiente focadas nas } \\
\text { interações informais, em relações de poder } \\
\text { e no processo constitutivo das instituições, } \\
\text { enfatizando a heterogeneidade do universo } \\
\text { organizacional. Em sua retomada, em fins } \\
\text { dos anos 1970, as relações de poder são } \\
\text { colocadas em segundo plano e evidenciam- } \\
\text { se requisitos de conformidade a padrões } \\
\text { institucionalmente legitimados, ressaltando } \\
\text { a homogeneidade entre conjuntos de } \\
\text { organizações. }\end{array}$ \\
\hline
\end{tabular}

Quadro 2: Principais vertentes da teoria institucional Fonte: Carvalho, Vieira e Goulart (2005, p. 855)

O Quadro 2 evidencia as vertentes históricas relacionadas à teoria institucional, sendo que, para fins deste estudo, será abordado o enfoque sociológico, tendo em vista que essa vertente tem prevalecido no campo dos estudos organizacionais, pois possibilita uma maior compreensão sobre as dimensões ambientais, na medida em que valoriza propriedades simbólico-normativas das estruturas. (CARVALHO, VIEIRA E GOULART, 2005)

Selznick (1972), um dos precursores da teoria institucional no âmbito organizacional, diferencia organização e instituição. Para o autor, organização "[...] é um instrumento técnico para a mobilização das energias humanas, que visa uma finalidade já estabelecida e refere-se a um instrumento perecível e racional projetado para executar um serviço [...]", já instituição "[...] consiste em um organismo adaptativo originado a partir de um processo natural de equilíbrio das pressões sociais." (SELZNICK, 1972, p. 5) 
O trabalho de Meyer e Rowan (1977) traz uma nova conotação para a teoria institucional, ao enfatizar que as organizações formais surgem como reflexos da racionalização das regras institucionais que funcionam como mitos, os quais as organizações incorporam, a fim de ganhar legitimidade, recursos, estabilidade e maiores chances de sobrevivência.

Barbieri et al. (2010) ressaltam que a explicação para a difusão do conceito de desenvolvimento sustentável no meio empresarial pode ser encontrada na teoria institucional a partir do argumento de Meyer e Rowan (1977) de que as organizações incorporam práticas institucionalizadas na sociedade, que se tornam mitos a serem seguidos, $e$ visam aumentar a legitimidade e as condições de sobrevivência das organizações.

As empresas são pressionadas a adotarem modelos vistos como ideais, institucionalizados no setor e na sociedade, sendo que os valores ligados ao desenvolvimento sustentável $e$ ao respeito às políticas ambientais têm sido institucionalizados em maior ou menor grau nos diversos países pela mídia, pelos movimentos sociais e ambientalistas e pelos governos. (BARBIERI et al., 2010)

As pressões exercidas sob as organizações que levam à adoção de práticas institucionalizadas podem ser explicadas por meio do isomorfismo, que consiste em um processo de restrição que força uma unidade em uma população a se assemelhar a outras unidades que enfrentam o mesmo conjunto de condições ambientais. (HAWLEY, 1968 apud DIMAGGIO; POWELL, 2005)

Para DiMaggio e Powell (2005), existem dois tipos de isomorfismo: o competitivo e o institucional, sendo o último mais adequado para compreender as mudanças do ambiente organizacional moderno. Os autores (2005) identificam ainda três tipos de mecanismos isomórficos institucionais: o coercitivo, o mimético e o normativo.

$\mathrm{O}$ isomorfismo coercitivo resulta de pressões formais e informais que uma organização mais forte exerce sobre outra que lhe seja dependente, e de expectativas culturais da sociedade. As ordens governamentais muitas vezes explicam as mudanças organizacionais em decorrência do isomorfismo coercitivo, como, por exemplo, os produtores adotam novas tecnologias para se adequarem às regulamentações ambientais. $\mathrm{O}$ isomorfismo mimético decorre de situações de incerteza que impulsionam a imitação. A tendência de seguir outras organizações como modelo deriva da incerteza e pode ocorrer em situações como quando as metas organizacionais são ambíguas, o ambiente se revela incerto ou os recursos tecnológicos de que a organização dispõe são limitados. Geralmente, as organizações que servem de modelo tendem a ser mais bem-sucedidas ou legítimas. E por fim, o isomorfismo normativo deriva principalmente da profissionalização e da definição de métodos e condições de trabalho para uma determinada classe profissional, ou do estabelecimento de normas. (DIMAGGIO; POWELL, 2005)

A incorporação de práticas institucionalizadas na sociedade pelas empresas visando à obtenção de legitimidade e de condições de sobrevivência (MEYER; ROWAN, 1977) e os processos de isomorfismo como fatores explicadores do comportamento empresarial em virtude das pressões exercidas pela sociedade para a adoção de tais práticas (DIMAGGIO; POWELL, 2005; BARBIERI et al., 2010) foram utilizados como base para análise da adoção de práticas de gestão para a sustentabilidade.

\section{Método do Estudo}

O estudo caracteriza-se como exploratório e qualitativo e tem como intuito analisar as principais práticas de gestão para a sustentabilidade das empresas minerais. A adoção de práticas de gestão para a sustentabilidade foi analisada por meio dos dez princípios para o desenvolvimento sustentável do International Council on Mining and Metals (2008), agrupados em três categorias de análise: práticas de gestão relacionadas ao comportamento ético, práticas de gestão ambiental e social.

O Quadro 3 resume as categorias de análise do estudo.

A partir do modelo conceitual, foi elaborado o pressuposto que embasou a análise da pesquisa:

P1: A adoção de práticas de gestão para a sustentabilidade está relacionada ao processo de isomorfismo. (DIMAGGIO; POWELL, 2005)

O pressuposto elaborado a partir do referencial teórico buscou analisar empiricamente, nas organizações estudadas, o atendimento dos critérios previamente definidos. 


\section{GESTÃo PARA A SUSTENTABILIDADE}

\begin{tabular}{|c|c|}
\hline Categorias de Análise & VARIÁVEIS \\
\hline $\begin{array}{l}\text { Práticas de gestão } \\
\text { relacionadas ao } \\
\text { comportamento ético. }\end{array}$ & $\begin{array}{l}\text { - Integração da ética nas práticas comerciais. } \\
\text { - Integração do desenvolvimento sustentável no processo de tomada de decisões } \\
\text { corporativas. } \\
\text { - Estratégias de gestão de risco ambiental e de segurança. } \\
\text { - Acordos efetivos e transparentes com as partes interessadas para o comprometimento, } \\
\text { a comunicação e a verificação independente das informações. }\end{array}$ \\
\hline Práticas de gestão ambiental & $\begin{array}{l}\text { - Avaliação global e periódica dos impactos da atividade empresarial nos ecossistemas } \\
\text { e comunidade. } \\
\text { - Melhoria contínua nas áreas de saúde e segurança. } \\
\text { - Melhoria contínua na área ambiental. } \\
\text { - Conservação da biodiversidade e das abordagens integradas ao planejamento do uso } \\
\text { da terra. } \\
\text { - Gerenciamento integrado dos materiais utilizados em toda a cadeia mineral. }\end{array}$ \\
\hline Práticas de gestão social & $\begin{array}{l}\text { - Estratégias de defesa dos direitos humanos fundamentais e respeito à cultura, aos } \\
\text { costumes e aos valores dos stakeholders. } \\
\text { - Promoção do desenvolvimento social, econômico e institucional das comunidades. }\end{array}$ \\
\hline
\end{tabular}

Quadro 3: Dimensões e categorias de análise

Fonte: Elaborado a partir de International Council on Mining and Metals (2008)

\subsection{Seleção de Casos}

Para a realização do estudo foram selecionadas três empresas pertencentes ao setor mineral, tendo como principal critério de seleção a acessibilidade. As empresas foram denominadas, para fins deste estudo, como Empresa Calcário (ECAL), Empresa Carvão (ECAR) e Empresa Ferro (EFER). Os nomes fictícios correspondem aos principais produtos minerais das organizações estudadas. As empresas Calcário e Carvão estão localizadas no estado do Rio Grande do Sul; e a empresa Ferro está instalada no estado de Minas Gerais. De acordo com a receita operacional bruta do ano de $2010^{1}$, as empresas caracterizam-se como de portes médio, médio-grande e grande, respectivamente.

\subsection{Procedimentos para a Coleta e Análise dos Dados}

Os dados foram coletados a partir de fontes primárias e secundárias, como entrevistas semiestruturadas, documentos disponibilizados pelas empresas e consultas a websites. As entrevistas foram realizadas com os principais responsáveis pelas atividades socioambientais indicados pela direção das empresas no período de março a julho de 2011.

1 De acordo com a classificação do Banco Nacional de Desenvolvimento Econômico e Social - BNDES.
Para a análise dos dados utilizou-se a técnica de análise de conteúdo, que, segundo as proposições de Bardin (2002), trata-se do desvendamento de significações de diferentes tipos de discursos, baseando-se na inferência ou dedução, mas que, simultaneamente, respeita critérios específicos propiciadores de dados em frequência, em estruturas temáticas, entre outros. As categorias do modelo conceitual foram utilizadas para fins de organização e apresentação dos resultados.

\section{Análise e Discussão dos Resultados}

Os resultados são descritos a partir de três categorias de análise: perfil dos entrevistados, caracterização das empresas e práticas de gestão para a sustentabilidade.

\subsection{Perfil dos Entrevistados}

O perfil dos entrevistados é apresentado no Quadro 4.

Os entrevistados das empresas Calcário e Carvão possuem larga experiência no setor e na empresa e ambos são engenheiros químicos e possuem pós-graduação. A entrevistada da empresa Ferro possui menor experiência, o que permitirá a comparação 


\begin{tabular}{|l|l|l|l|l|}
\hline EMPRESA & \multicolumn{1}{|c}{ CARGo } & $\begin{array}{c}\text { ANO DE INGRESSO } \\
\text { NA EMPRESA }\end{array}$ & $\begin{array}{c}\text { TEMPO DE ATUAÇão } \\
\text { NO SETOR }\end{array}$ & \multicolumn{1}{c|}{ FormaçÃo } \\
\hline Calcário & $\begin{array}{l}\text { Engenheira Química e da } \\
\text { Segurança do Trabalho } \\
\text { e Coordenadora } \\
\text { da qualidade }\end{array}$ & 2000 & 11 anos & $\begin{array}{l}\text { Engenheira química e pós- } \\
\text { graduada em segurança do } \\
\text { trabalho e gestáo ambiental. }\end{array}$ \\
\hline Carvão & $\begin{array}{l}\text { Gerente de Controle } \\
\text { de Qualidade }\end{array}$ & 1982 & 29 anos & $\begin{array}{l}\text { Engenheiro químico e pós- } \\
\text { graduado em segurança } \\
\text { do trabalho, tratamento de } \\
\text { resíduos e carvão mineral. }\end{array}$ \\
\hline Ferro & Analista Ambiental & 2007 & 5 anos & Bióloga. \\
\hline
\end{tabular}

Quadro 4: Perfil dos entrevistados etapa qualitativa

Fonte: Dados da pesquisa

entre visões distintas de profissionais mais e menos experientes.

\subsection{Caracterização das Empresas}

A empresa Calcário (ECAL) foi fundada em 1918 e está localizada na região Sudeste do estado do Rio Grande do Sul, possui uma gestão familiar e tem como principais produtos cal, calcário e argamassa. Possui 310 funcionários e caracteriza-se como de médio porte, considerando a sua receita operacional bruta em 2010. Certificada pela norma ISO 9001 desde 2003, a empresa busca estabelecer um modelo de gestão de qualidade, e está começando a implantar um sistema integrado de gestão a fim de obter as certificações ISO 14001 relacionada à gestão ambiental e Occupational Health and Safety Advisory Services (OHSAS) 18001, que trata da segurança e saúde ocupacional.

A empresa Carvão (ECAR) atua no mercado de extração de carvão mineral desde 1883 e mantém atividades no Rio Grande do Sul, nos municípios de Porto Alegre, Butiá, Minas do Leão, Cachoeira do Sul, Charqueadas e Triunfo e também possui um escritório de desenvolvimento no Rio de Janeiro. A empresa detém $18 \%$ do total do mercado de carvão mineral nacional, atendendo desde o setor termelétrico até outras indústrias, como petroquímica, celulose, alimentação e cimento. Possui cerca de 920 empregados, sendo 320 diretos e em torno de 600 indiretos. Caracteriza-se como de médio-grande porte considerando a sua receita operacional bruta em 2010 e está certificada pela norma ISO 14001 desde 2008.

A empresa Ferro (EFER) pertence a um grupo que atua em quatro eixos de negócios: mineração, siderurgia, transformação do aço e bens de capital. Atua desde 2008 na região de Serra Azul, no quadrilátero ferrífero do estado de Minas Gerais, além de possuir uma área na Baía de Sepetiba, no Rio de Janeiro, na qual desenvolve estudos para a instalação de um terminal portuário. A empresa atua na lavra e beneficiamento de minério de ferro, possuindo quatro ativos minerários e está capacitada para transformar o ferro em pellet feed, sinter feed e granulados ${ }^{2}$. A produção é destinada ao consumo próprio nas plantas siderúrgicas da empresa e também à exportação. A empresa Ferro possui 2.785 funcionários, sendo 1.303 indiretos e 1.482 diretos. Considerando a sua receita operacional bruta em 2010, caracteriza-se como uma empresa de grande porte.

Em julho de 2011, a empresa recebeu a certificação ISO 9001 (gestão da qualidade) e está em fase de implantação da ISO 14001 (gestão ambiental).

No Quadro 5, é apresentada uma síntese das principais características das empresas pesquisadas, considerando-se os seguintes aspectos: ano de fundação, localização, principais produtos, porte, origem do capital controlador, certificações, divulgação de relatórios de sustentabilidade.

2 De acordo com o DNPM (2009), o minério bruto de ferro, após o beneficiamento, gera produtos classificados como granulados (acima de 6,3mm) e finos (sinterfeed - entre 0,15 e 6,3mm e pelletfeed - abaixo de 0,15mm). 


\begin{tabular}{|c|c|c|c|}
\hline $\begin{array}{l}\text { CARACTERÍSTICAS } \\
\text { OrganizaCIONAIS }\end{array}$ & Empresa CalcáRIO & EMPREsa Carvão & EMPRESA FERRO \\
\hline Ano de fundação & 1918 & 1883 & 2008 \\
\hline Localização & $\begin{array}{l}\text { Região Sudeste do } \\
\text { estado do estado do } \\
\text { Rio Grande do Sul }\end{array}$ & $\begin{array}{l}\text { Regiões Metropolitana } \\
\text { de Porto Alegre e } \\
\text { Centro Oriental Rio- } \\
\text { Grandense do estado } \\
\text { do Rio Grande do Sul }\end{array}$ & $\begin{array}{l}\text { Região de Serra Azul do } \\
\text { estado de Minas Gerais }\end{array}$ \\
\hline Principais produtos & Cal, calcário e argamassa & Carvão mineral & $\begin{array}{l}\text { Ferro (pellet feed, sinter } \\
\text { feed e granulados) }\end{array}$ \\
\hline Número de funcionários & 310 funcionários & $\begin{array}{l}920 \text { funcionários, sendo } \\
320 \text { diretos e } 600 \text { indiretos. }\end{array}$ & $\begin{array}{l}2785 \text { funcionários, } \\
\text { sendo } 1303 \text { indiretos } \\
\text { e } 1482 \text { diretos. }\end{array}$ \\
\hline $\begin{array}{l}\text { Porte de acordo com } \\
\text { receita bruta em } 2010\end{array}$ & Médio & Médio-grande & Grande \\
\hline $\begin{array}{l}\text { Origem do capital } \\
\text { controlador }\end{array}$ & Nacional & Nacional & Nacional \\
\hline Certificações & $\begin{array}{c}\text { ISO } 9001 \\
\text { Em fase de implantação } \\
\text { da ISO } 14001\end{array}$ & ISO 14001 & $\begin{array}{c}\text { ISO } 9001 \\
\text { Em fase de implantação } \\
\text { da ISO } 14001\end{array}$ \\
\hline $\begin{array}{l}\text { Divulgam relatório de } \\
\text { sustentabilidade }\end{array}$ & Sim & Não & $\operatorname{Sim}$ \\
\hline
\end{tabular}

Quadro 5: Caracterização das empresas analisadas

Fonte: Dados da pesquisa

A análise das principais características organizacionais evidencia a existência de empresas centenárias com larga experiência no mercado. Ao mesmo tempo, observa-se que uma das empresas pesquisadas ingressou nesse mercado há menos de cinco anos. Os tipos de minerais extraídos e o porte empresarial também são distintos.

\subsection{Práticas de Gestão para a Sustentabilidade}

As práticas de gestão sustentáveis foram estudadas a partir de três dimensões de análise: práticas de gestão relacionadas ao comportamento ético, práticas de gestão ambiental e social, definidas a partir do agrupamento dos princípios para a sustentabilidade no setor mineral do International Council on Mining and Metals (2008).

\subsubsection{Práticas de Gestão Relacionadas ao Comportamento Ético}

As práticas de gestão relacionadas ao comportamento ético foram identificadas por meio das seguintes categorias: integração da ética nas práticas comerciais, integração do desenvolvimento sustentável no processo de tomada de decisões corporativas, estratégias de gestão de risco ambiental e de segurança, acordos efetivos e transparentes com as partes interessadas para o comprometimento, a comunicação e a verificação independente das informações. O Quadro 6 resume as práticas de gestão $e$ as evidências relacionadas ao comportamento ético das empresas estudadas. 


\section{Práticas de gestão Relacionadas aO COMPORTAMENTo Ético}

\section{INTEGRAÇ̃̃o DA ÉTICA NAS PRÁTICAS COMERCIAIS}

\begin{tabular}{|c|c|c|}
\hline EMPRESA & Práticas sustentá & EVIDÊNCIAS \\
\hline \multirow[b]{2}{*}{ Calcário (ECAL) } & $\begin{array}{l}\text { Ética como um } \\
\text { dos valores }\end{array}$ & "A ética faz parte dos valores da nossa empresa". \\
\hline & $\begin{array}{l}\text { Sistema de Gestão } \\
\text { da Qualidade }\end{array}$ & $\begin{array}{l}\text { "A ISO dá uma padronização de todos os processos, credibilidade } \\
\text { maior, o sistema de gestão garante a transparência e compromisso com } \\
\text { as partes interessadas". }\end{array}$ \\
\hline Carvão (ECAR) & $\begin{array}{l}\text { Conduta pautada } \\
\text { pela ética }\end{array}$ & $\begin{array}{l}\text { "Temos uma postura comercial, ambiental que nos leva sempre a ter } \\
\text { práticas eticamente corretas". }\end{array}$ \\
\hline Ferro (EFER) & $\begin{array}{l}\text { Diretrizes estratégicas } \\
\text { pautadas pela ética }\end{array}$ & "Uma das diretrizes estratégicas da nossa empresa é pautada pela ética." \\
\hline
\end{tabular}

INTEGRAÇÃo DO DESENVOLVIMENTO SUSTENTÁVEL NO PROCESSO DE TOMADA DE DECISÕES CORPORATIVAS

\begin{tabular}{|c|c|c|}
\hline \multirow{2}{*}{ Calcário (ECAL) } & $\begin{array}{l}\text { Ações sociais e } \\
\text { ambientais }\end{array}$ & $\begin{array}{l}\text { "Já fazemos muito mais em comparação aos outros, mas o que } \\
\text { possuímos são ações sociais e ambientais, muito mais sociais". }\end{array}$ \\
\hline & $\begin{array}{l}\text { Sistema integrado } \\
\text { de gestão }\end{array}$ & $\begin{array}{l}\text { "[...] estamos contratando uma empresa para montar esse sistema } \\
\text { integrado visando a ISO 14001". }\end{array}$ \\
\hline \multirow{3}{*}{ Carvão (ECAR) } & $\begin{array}{l}\text { Programas sociais } \\
\text { e ambientais. }\end{array}$ & $\begin{array}{l}\text { "Para o crescimento da empresa é fundamental a sua integração com } \\
\text { os colaboradores, clientes, fornecedores e as comunidades onde atua } \\
\text { a partir de diversos programas direcionados à responsabilidade social". }\end{array}$ \\
\hline & Certificação ISO 14001. & $\begin{array}{l}\text { "a empresa foi buscar sim a ISO } 14001 \text { porque é um sistema que se } \\
\text { bem trabalhado os teus riscos ambientais estarão minimizados". }\end{array}$ \\
\hline & $\begin{array}{l}\text { Relação harmoniosa } \\
\text { com a comunidade }\end{array}$ & $\begin{array}{l}\text { "é melhor estrategicamente você manter um diálogo bom com a } \\
\text { comunidade, que é de onde sai a nossa mão de obra e gera recurso". }\end{array}$ \\
\hline \multirow[t]{2}{*}{ Ferro (EFER) } & $\begin{array}{l}\text { Emprego de novas } \\
\text { tecnologias e } \\
\text { atendimento dos } \\
\text { requisitos ambientais }\end{array}$ & $\begin{array}{l}\text { "Reconhecemos o cenário econômico buscando a empregar novas } \\
\text { tecnologias para minimizar impactos ambientais, atender os quesitos } \\
\text { ambientais aplicáveis para a minimização de interferências no meio". }\end{array}$ \\
\hline & $\begin{array}{l}\text { Implantação de um } \\
\text { sistema de gestão }\end{array}$ & $\begin{array}{l}\text { "Estamos implementando um sistema integrado de gestão visando às } \\
\text { certificações ISO } 14001 \text { e OHSAS 18001". }\end{array}$ \\
\hline \multicolumn{3}{|c|}{ ESTRATÉGIAS DE GESTÃo DE RISCO AMBIENTAL E DE SEGURANÇA } \\
\hline \multirow{3}{*}{ Calcário (ECAL) } & $\begin{array}{l}\text { Monitoramento do } \\
\text { impacto ambiental }\end{array}$ & $\begin{array}{l}\text { "Uma empresa monitora toda essa parte de impacto, então tem um } \\
\text { monte de coisas que a gente já faz para atender". }\end{array}$ \\
\hline & $\begin{array}{l}\text { Plantio de árvores } \\
\text { nativas e frutíferas }\end{array}$ & $\begin{array}{l}\text { "Recuperamos as jazidas que já foram exploradas e, se planta em cima } \\
\text { dessa área, árvores nativas, frutíferas e não frutíferas". }\end{array}$ \\
\hline & $\begin{array}{l}\text { Segurança dos } \\
\text { colaboradores é parte } \\
\text { dos valores da empresa. }\end{array}$ & $\begin{array}{l}\text { "As questões de segurança e prevenção de acidentes são de extrema } \\
\text { importância para a empresa, a segurança dos colaboradores sempre } \\
\text { esteve presente nas rotinas de nossas equipes desde a nossa fundação". }\end{array}$ \\
\hline \multirow{2}{*}{ Carvão (ECAR) } & $\begin{array}{l}\text { Sistema de gestão } \\
\text { certificado pela } \\
\text { ISO } 14001 \text {. }\end{array}$ & $\begin{array}{l}\text { "(...) uma das primeiras providências para minimizar os riscos ambientais } \\
\text { era estar com o sistema de gestão, efetivo, normatizado, reconhecido } \\
\text { e implantado, além de ter um corpo qualificado, a empresa foi buscar } \\
\text { sim a ISO 14001." }\end{array}$ \\
\hline & $\begin{array}{l}\text { Análise de perigos e } \\
\text { riscos e programas } \\
\text { de saúde e segurança } \\
\text { ocupacional. }\end{array}$ & $\begin{array}{l}\text { "Os programas de gestão de saúde e segurança } \\
\text { ocupacional são elaborados com base no levantamento } \\
\text { e identificação de perigos e riscos significativos." }\end{array}$ \\
\hline Ferro (EFER) & $\begin{array}{l}\text { Implantação da } \\
\text { gestão de risco. }\end{array}$ & "Estamos em fase de estruturação de gestão de risco". \\
\hline
\end{tabular}




\section{Práticas de gestão Relacionadas ao comportamento ético}

\section{ACORDOS EFETIVOS E TRANSPARENTES COM AS PARTES INTERESSADAS PARA O COMPROMETIMENTO, A COMUNICA- ÇÃO E A VERIFICAÇÃO INDEPENDENTE DAS INFORMAÇÕES}

\begin{tabular}{lll} 
Calcário (ECAL) & $\begin{array}{l}\text { Canais de comunicação } \\
\text { com as partes } \\
\text { interessadas. }\end{array}$ & $\begin{array}{l}\text { "A empresa possui alguns canais como fale conosco no site, } \\
\text { informativo, divulgação na mídia das ações empresariais". }\end{array}$ \\
\hline Carvão (ECAR) & $\begin{array}{l}\text { Relacionamento com a } \\
\text { comunidade do entorno. }\end{array}$ & $\begin{array}{l}\text { "divulga para todos do público interno e externo a hora que } \\
\text { tem detonação, dando a melhor transparência possível". }\end{array}$ \\
\hline Ferro (EFER) & Canal Aberto & $\begin{array}{l}\text { "O canal aberto cria um espaço de comunicação aos colaboradores, } \\
\text { clientes, fornecedores, investidores e à sociedade em geral." }\end{array}$
\end{tabular}

Quadro 6: Práticas de gestão relacionadas ao comportamento ético

Fonte: Dados da pesquisa

De modo geral, evidenciou-se que as empresas analisadas procuram adotar práticas comerciais éticas e integrar o desenvolvimento sustentável no processo de tomada de decisões por meio de ações sociais e ambientais e da busca por certificações como a ISO 14001. Essa tendência é corroborada por Amade e Lima (2009), ao ressaltarem que os princípios de desenvolvimento sustentável incluem a avaliação dos valores morais e éticos e também a consideração dos valores subjetivos da comunidade. Nesse sentido, foi possível verificar que a gestão de risco ambiental e de segurança está presente nas empresas ECAL e ECARe encontra-se ainda em fase de implantação na empresa EFER. Além disso, as empresas possuem algum canal de comunicação com as partes interessadas.

Observa-se que, embora as empresas analisadas afirmem que a ética faz parte dos seus valores e dire- trizes, foram constatadas poucas ações relacionadas a esta dimensão de análise. Também as empresas relacionam demasiadamente as práticas de gestão relacionadas ao comportamento ético com a busca por certificações.

\subsubsection{Práticas de Gestão Ambiental}

As práticas de gestão ambiental foram identificadas de acordo com as seguintes categorias: avaliação global e periódica dos impactos da atividade empresarial nos ecossistemas e na comunidade, melhoria contínua na área ambiental, conservação da biodiversidade e das abordagens integradas ao planejamento do uso da terra, gerenciamento integrado dos materiais utilizados em toda a cadeia mineral. O Quadro 7 resume as práticas de gestão ambiental das empresas analisadas.

\section{Práticas de gestão ambiental}

\begin{tabular}{|c|c|c|}
\hline EMPRESA & Práticas SUSTENTÁveis & EVIDÊNCIAS \\
\hline Calcário (ECAL) & $\begin{array}{l}\text { Atendimento da legislação e } \\
\text { estudos de impacto ambiental. }\end{array}$ & $\begin{array}{l}\text { "[...] nós temos que atender um monte de coisas. A gente tem uma } \\
\text { empresa que monitora toda essa parte, toda essa parte de impacto". }\end{array}$ \\
\hline Carvão (ECAR) & $\begin{array}{l}\text { Atendimento da legislação e } \\
\text { estudos de impacto ambiental. }\end{array}$ & $\begin{array}{l}\text { "Cada área de atuação terá que ter um enfoque, que começa a } \\
\text { ficar definido quando começamos a fazer os estudos de impacto } \\
\text { ambiental, por força de lei nós temos que, além desses fazer os } \\
\text { chamados PAL e RAL exigidos pelo DNPM, além dos aspectos } \\
\text { ambientais de FEPAM e outros". }\end{array}$ \\
\hline Ferro (EFER) & Estudos de impacto ambiental. & "Esta avaliação está integrada nos estudos de impactos ambientais". \\
\hline
\end{tabular}

Quadro 7: Práticas de gestão ambiental desenvolvidas pelas empresas

Fonte: Dados da pesquisa 


\begin{tabular}{|c|c|c|}
\hline \multicolumn{3}{|c|}{ MelHoria CONTÍNUA NA ÁREA AMBIENTAL } \\
\hline EMPRESA & Práticas sustentáveis & EvidÊNCIAS \\
\hline \multirow{2}{*}{ Calcário (ECAL) } & $\begin{array}{l}\text { Consolidação com a } \\
\text { implantação da ISO } 14001 .\end{array}$ & $\begin{array}{l}\text { "Vamos buscar a partir da implantação do sistema integrado de } \\
\text { gestão". }\end{array}$ \\
\hline & $\begin{array}{l}\text { Ações a fim de minimizar } \\
\text { os impactos ambientais. }\end{array}$ & $\begin{array}{l}\text { "Nós temos o plantio de árvores frutíferas e nativas, coleta seletiva, } \\
\text { coleta de lixo eletrônico, pilhas e baterias". }\end{array}$ \\
\hline \multirow[b]{2}{*}{ Carvão (ECAR) } & Certificação ISO 14001. & $\begin{array}{l}\text { "Para minimizar os riscos ambientais a empresa foi buscar a ISO } \\
14001, \text { o que nos colocou em um bom patamar para minimizar os } \\
\text { riscos ambientais, e também fez com que tivéssemos que retroagir } \\
\text { em busca da eliminação de passivos ambientais". }\end{array}$ \\
\hline & $\begin{array}{l}\text { Mitigação dos impactos } \\
\text { ambientais de suas operações. }\end{array}$ & $\begin{array}{l}\text { "Controlamos a poeira, ruídos e possíveis intervenções nas águas } \\
\text { subterrâneas e pluviais. Também a empresa começa a olhar o seu } \\
\text { passado, com uma atividade que se iniciou há mais de } 100 \text { anos, onde } \\
\text { naquela época não tinha tecnologia como se tem hoje, então alguma } \\
\text { coisa pode ter ficado enviesada, então hoje também resgatamos". }\end{array}$ \\
\hline \multirow{2}{*}{ Ferro (EFER) } & $\begin{array}{l}\text { Gestão do controle ambiental e } \\
\text { emprego de novas tecnologias. }\end{array}$ & $\begin{array}{l}\text { "A empresa realiza a gestão do controle ambiental dos processos } \\
\text { avaliando a empregabilidade de novas tecnologias". }\end{array}$ \\
\hline & Sistema Integrado de Gestão. & $\begin{array}{l}\text { "A empresa está em fase de implementação do Sistema Integrado } \\
\text { de Gestão visando às certificações ISO } 14001 \text { e OHSAS 18001". }\end{array}$ \\
\hline \multicolumn{3}{|c|}{ CONSERVAÇÃO DA BIODIVERSIDADE E DAS ABORDAGENS INTEGRADAS AO PLANEJAMENTO DO USO DA TERRA } \\
\hline \multirow[b]{2}{*}{ Calcário (ECAL) } & $\begin{array}{l}\text { Recuperação das } \\
\text { áreas degradadas. }\end{array}$ & $\begin{array}{l}\text { "Recuperamos as áreas onde não há mais exploração, em uma jazida } \\
\text { desativada, nós criamos peixe, plantamos árvores toda a volta". }\end{array}$ \\
\hline & $\begin{array}{l}\text { Palestras importância da } \\
\text { correção do solo nas culturas. }\end{array}$ & $\begin{array}{l}\text { "Nós temos o produto calcário que é exatamente para a correção do } \\
\text { solo, então fazemos palestras falando da importância da correção } \\
\text { do solo nas culturas". }\end{array}$ \\
\hline \multirow{2}{*}{ Carvão (ECAR) } & $\begin{array}{l}\text { Continuidade de utilização sócio } \\
\text { econômica da área explorada. }\end{array}$ & $\begin{array}{l}\text { "uma vez cessada a atividade mineira, tudo precisa estar configurado } \\
\text { para dar continuidade a atividade antes desempenhada". }\end{array}$ \\
\hline & $\begin{array}{l}\text { Programa de incentivo } \\
\text { ao plantio de mudas. }\end{array}$ & $\begin{array}{l}\text { "São desenvolvidas atividades de plantio de mudas nativas, visando } \\
\text { o equilíbrio do meio ambiente". }\end{array}$ \\
\hline \multirow[b]{2}{*}{ Ferro (EFER) } & $\begin{array}{l}\text { Planejamento do uso e } \\
\text { ocupação do solo. }\end{array}$ & $\begin{array}{l}\text { "Nós planejamos o uso e ocupação do solo, monitoramos a } \\
\text { mastofauna das áreas circunvizinhas e áreas de preservação". }\end{array}$ \\
\hline & $\begin{array}{l}\text { Programa de áreas verdes, } \\
\text { paisagismo interno da área } \\
\text { industrial e plantio de mudas. }\end{array}$ & $\begin{array}{l}\text { "A empresa possui um programa de áreas verdes e paisagismo } \\
\text { interno da área industrial, mantido por meio do viveiro de mudas". }\end{array}$ \\
\hline \multicolumn{3}{|c|}{ GERENCIAMENTO INTEGRADO DOS MATERIAIS UTILIZADOS EM TODA A CADEIA MINERAL } \\
\hline \multirow{2}{*}{ Calcário (ECAL) } & $\begin{array}{l}\text { Coleta seletiva e de } \\
\text { resíduos especiais. }\end{array}$ & $\begin{array}{l}\text { "fazemos a coleta seletiva, de lâmpadas fluorescentes, pneus, o } \\
\text { material da manutenção com óleos graxos, nós também recolhemos } \\
\text { as pilhas, as baterias, o lixo eletrônico". }\end{array}$ \\
\hline & $\begin{array}{l}\text { Cartilha sobre a utilização, } \\
\text { reutilização, reciclagem, redução } \\
\text { e descarte de resíduos. }\end{array}$ & $\begin{array}{l}\text { "estamos fazendo uma cartilha em relação a utilização, reutilização, } \\
\text { reciclagem, redução, descarte das próprias lâmpadas, óleos graxos, } \\
\text { produtos químicos". }\end{array}$ \\
\hline \multirow[b]{2}{*}{ Carvão (ECAR) } & $\begin{array}{l}\text { Rejeitos retornam para a cavidade } \\
\text { aberta durante a exploração }\end{array}$ & "os meus rejeitos voltam pra cava da mina". \\
\hline & $\begin{array}{l}\text { Palestras e oficinas sobre } \\
\text { a importância de reduzir, } \\
\text { reutilizar e reciclar. }\end{array}$ & $\begin{array}{l}\text { "A empresa busca através de palestras e oficinas conscientizar os } \\
\text { colaboradores e a comunidade do entorno da importância de } \\
\text { reduzir, reutilizar e reciclar". }\end{array}$ \\
\hline Ferro (EFER) & $\begin{array}{l}\text { Implementação do } \\
\text { Gerenciamento de resíduos. }\end{array}$ & $\begin{array}{l}\text { "Somente teremos práticas consolidadas a partir da implantação do } \\
\text { sistema integrado de gestão e obtenção da ISO 14001". }\end{array}$ \\
\hline
\end{tabular}

Quadro 7: Práticas de gestão ambiental desenvolvidas pelas empresas

Fonte: Dados da pesquisa 
O estudo apresentou evidências de que, em relação às práticas de gestão ambiental, as empresas analisadas possuem uma atitude apenas reativa $e$ estão preocupadas em atender aos requisitos legais e às exigências mercadológicas, investindo apenas em certificações e possuem poucas práticas de gestão. Esse resultado corrobora com as conclusões de Enríquez (2009), quando ele afirma que o Brasil, desde os anos de 1980, vem estruturando uma ampla base regulatória no que se refere à temática ambiental, particularmente relacionada à mineração. Tal fato fez com que as empresas mineradoras se adequassem às exigências legais e também do mercado e da sociedade, que passou a exigir uma postura socioambiental proativa das empresas.

Em estudo realizado em grandes municípios mineradores brasileiros, Enríquez (2009) constatou que as minas mais recentes apresentam uma postura protiva ambiental, ao contrário das minas antigas. No presente estudo, foram investigadas organizações centenárias, como as empresas ECAL e ECAR, sendo que a primeira ainda está buscando a consolidação do seu sistema de gestão ambiental e a segunda, apesar de estar certificada, adotou essa postura nos últimos cinco anos. A empresa EFER, a mais jovem das empresas estudadas, está buscando as certificações ambientais, assim como a consolidação do seu sistema de gestão.

A preocupação com o contexto ambiental é evidenciada nas empresas analisadas, entretanto essa postura ainda é bastante recente e reativa, decorrente, sobretudo, de aspectos legais, embora se possa observar a adesão a instrumentos voluntários, como as certificações.

\subsubsection{Práticas de Gestão Social}

As práticas de gestão social foram analisadas com base nas seguintes categorias: estratégias de defesa dos direitos humanos fundamentais e respeito à cultura, aos costumes e aos valores dos stakeholders, promoção do desenvolvimento social, econômico e institucional das comunidades, melhoria contínua nas áreas de saúde e segurança. o Quadro 8 resume as práticas de gestão social das empresas estudadas.

\begin{tabular}{|c|c|c|}
\hline \multicolumn{3}{|c|}{ PRÁtICAS DE GESTÃo SOCIAL } \\
\hline EMPRESA & Práticas Sustentáveis & EVIDÊNCIAS \\
\hline \multicolumn{3}{|c|}{$\begin{array}{c}\text { ESTRATÉGIAS DE DEFESA DOS DIREITOS HUMANOS FUNDAMENTAIS E RESPEITO À CULTURA, AOS COSTUMES E AOS } \\
\text { VALORES DOS STAKEHOLDERS }\end{array}$} \\
\hline \multirow[b]{2}{*}{ Calcário (ECAL) } & $\begin{array}{l}\text { Ambiente de trabalho } \\
\text { reflete a diversidade. }\end{array}$ & $\begin{array}{l}\text { "Incentivar a diversidade, combater o preconceito e trabalhar para } \\
\text { eliminar as diferenças são exemplos éticos que a empresa busca." }\end{array}$ \\
\hline & $\begin{array}{l}\text { Ações sociais que envolvem os } \\
\text { funcionários e a comunidade. }\end{array}$ & $\begin{array}{l}\text { "temos uma vila ao lado da empresa, então temos que manter as } \\
\text { condições, até pouco tempo atrás quem recolhia o lixo todo da vila } \\
\text { era a empresa [...] nós temos vários projeto sociais". }\end{array}$ \\
\hline \multirow{3}{*}{ Carvão (ECAR) } & $\begin{array}{l}\text { Engajamento no processo } \\
\text { de responsabilidade social. }\end{array}$ & $\begin{array}{l}\text { "a empresa promove ações de conscientização sobre responsabilidade } \\
\text { social no ambiente de trabalho, no lar dos colaboradores e na } \\
\text { comunidade em geral". }\end{array}$ \\
\hline & $\begin{array}{l}\text { Programas sociais junto à } \\
\text { comunidade do entorno. }\end{array}$ & $\begin{array}{l}\text { "são realizadas oficinas de artesanato, conscientização ambiental e } \\
\text { palestras voltadas para a qualidade de vida". }\end{array}$ \\
\hline & $\begin{array}{l}\text { Multiplicadores da política } \\
\text { social da empresa. }\end{array}$ & $\begin{array}{l}\text { "promovemos a criação de grupos voluntários de multiplicadores } \\
\text { da política social da empresa através do teatro, música e outros } \\
\text { métodos lúdicos". }\end{array}$ \\
\hline \multirow{2}{*}{ Ferro (EFER) } & Código de conduta. & $\begin{array}{l}\text { "estabelecemos um código de conduta com princípios que norteiam } \\
\text { o relacionamento da empresa com os principais públicos em sua } \\
\text { atuação". }\end{array}$ \\
\hline & $\begin{array}{l}\text { Investimentos em } \\
\text { projetos sociais. }\end{array}$ & $\begin{array}{l}\text { "Em } 2010 \text { ampliamos os investimentos em projetos sociais, ao } \\
\text { mesmo tempo em que estreitamos o relacionamento com nossos } \\
\text { diferentes públicos de interesse". }\end{array}$ \\
\hline
\end{tabular}

Quadro 8: Práticas de gestão social desenvolvidas pelas empresas

Fonte: Dados da pesquisa 


\begin{tabular}{|c|c|c|}
\hline \multicolumn{3}{|c|}{ Promoção do DESENVOLVIMENTO SOCIAL, ECONÔMICO E INSTITUCIONAL DAS COMUNIDADES } \\
\hline Calcário (ECAL) & Programas sociais. & $\begin{array}{l}\text { "A empresa possui várias ações sociais junto à escola da comunidade, } \\
\text { como a semana do meio ambiente, programa de inclusão da pessoa } \\
\text { com deficiência, campanhas beneficentes". }\end{array}$ \\
\hline Carvão (ECAR) & Programas sociais. & $\begin{array}{l}\text { "Promovemos oficinas de artesanato, palestras, ações nas escolas, } \\
\text { participação em eventos, Projeto Operação Natal". }\end{array}$ \\
\hline Ferro (EFER) & Programas sociais. & $\begin{array}{l}\text { "Priorizamos a contratação de fornecedores locais a fim de fomentar } \\
\text { a economia da região, temos uma fundação, também apoiamos a } \\
\text { cultura e o esporte, promovemos campanhas beneficentes". }\end{array}$ \\
\hline \multicolumn{3}{|c|}{ 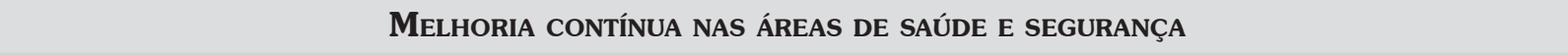 } \\
\hline \multirow{2}{*}{ Calcário ECAL) } & $\begin{array}{l}\text { Práticas para a saúde e } \\
\text { segurança dos colaboradores. }\end{array}$ & $\begin{array}{l}\text { "nós temos o monitoramento da poeira e do ruído, controle de } \\
\text { exames, treinamento de segurança, controle de EPIs, exames } \\
\text { admissionais e periódicos, campanhas de vacinação, controle de } \\
\text { todas as vacinas". }\end{array}$ \\
\hline & $\begin{array}{l}\text { Campanhas de } \\
\text { esclarecimentos e palestras } \\
\text { sobre segurança e saúde. }\end{array}$ & $\begin{array}{l}\text { "Realizamos anualmente a semana interna de prevenção de } \\
\text { acidentes a fim de colocar as questôes de segurança e prevenção } \\
\text { de acidentes no centro do debate". }\end{array}$ \\
\hline Carvão (ECAR) & $\begin{array}{l}\text { Programas de Gestão } \\
\text { de Saúde e Segurança } \\
\text { Ocupacional. }\end{array}$ & $\begin{array}{l}\text { "Lançamos o programa Boa vida, no qual vamos olhar todo o } \\
\text { ambiente que nós estamos envolvidos, porque não é mais só dar } \\
\text { o capacete é fazer os indivíduos sentirem-se bem no seu local de } \\
\text { trabalho". }\end{array}$ \\
\hline Ferro (EFER) & $\begin{array}{l}\text { Ações de saúde e } \\
\text { segurança do trabalho. }\end{array}$ & $\begin{array}{l}\text { "A empresa possui ações como campanhas de saúde e vacinação, } \\
\text { programas de prevenção de doenças, treinamentos sobre higiene } \\
\text { do trabalho e controle dos riscos, ações de orientação do Serviço } \\
\text { Social". }\end{array}$ \\
\hline
\end{tabular}

Quadro 8: Práticas de gestão social desenvolvidas pelas empresas

Fonte: Dados da pesquisa

No que se refere às práticas de gestão social, com base nos dados do Quadro 9, é possível concluir que as organizações analisadas apresentam ações relacionadas ao respeito aos stakeholders, principalmente no que se refere aos funcionários e à comunidade local. As empresas promovem o desenvolvimento das comunidades nas quais estão inseridas por meio de ações sociais e também desenvolvem práticas de melhoria contínua nas áreas de saúde e segurança.

A preocupação social está bastante presente nas empresas analisadas, principalmente com relação ao desenvolvimento de ações sociais junto às comunidades do entorno. Essa atitude vai de encontro ao pensamento de Solomon, Katz e Lovel (2008), quando eles constatam, em um estudo sobre a dimensão social do desenvolvimento sustentável na indústria mineral da Austrália, que a questão social é bastante ampla e complexa, e precisa ir além da ideia de "comunidade", sendo necessária uma mudança cultural para que as todas as perspectivas sociais sejam integradas e consideradas. Observa-se, assim, que, do mesmo modo, na indústria mineral brasileira faz-se necessário considerar a amplitude e complexidade da questão social.

\section{Considerações Finais}

O presente estudo, que teve como objetivo analisar a adoção de práticas de gestão para a sustentabilidade em empresas do setor mineral sob a perspectiva da teoria institucional, evidenciou que as práticas de gestão relacionadas ao comportamento ético estão demasiadamente pautadas pela busca por certificações e foram constatadas poucas ações relacionadas a esta dimensão de análise.

A preocupação social está bastante presente nas empresas do setor mineral estudadas, principalmente no que se refere ao desenvolvimento de ações sociais para a comunidade do entorno. O estudo apresentou evidências de que, em relação ao contexto ambiental, as empresas analisadas possuem uma atitude apenas reativa, voltada ao atendimento dos requisitos legais e 
das exigências mercadológicas, investindo apenas em certificações e em algumas práticas de gestão.

Evidenciou-se também que o comportamento das empresas estudadas, de modo geral, prioriza o atendimento das exigências legais e a busca por certificações a partir de normas como a ISO 14001, o que corrobora com o pressuposto: A adoção de práticas de gestão para a sustentabilidade está relacionada à legitimação das empresas mineradoras por meio do isomorfismo (DIMAGGIO; POWELL, 2005). As empresas estudadas são impulsionadas por mecanismos de isomorfismo coercitivo, a partir da influência formal dos órgãos governamentais e também isomorfismo normativo na medida em que se adaptam a normas reguladoras na busca por certificações

\section{REFERÊNCIAS}

ALIGLERI, L. M. A adoção de ferramentas de gestão para a sustentabilidade e a sua relação com os princípios ecológicos nas empresas. 2011. 170 p. Tese (Doutorado em Administração) - Universidade de São Paulo, São Paulo, 2011.

ALIGLERI, L.; ALIGLERI, L. A.; KRUGLIANSKAS,

I. Gestão socioambiental: responsabilidade e sustentabilidade do negócio. São Paulo: Atlas, 2009.

\section{ALMEIDA, F. O bom negócio da sustentabilidade.}

Rio de Janeiro: Nova Fronteira, 2002.

AMADE, P.; LIMA, H. M. de. Desenvolvimento sustentável e garimpo - O caso do Garimpo do Engenho Podre em Mariana, Minas Gerais. Revista Escola de Minas

Gerais - REM, Ouro Preto, v. 62, n. 2, abr.-jun. 2009, p. 237-242.

AZAPAGIC, A. Developing a framework for sustainable development indicators for the mining and minerals industry. Journal of Cleaner Production, v. 12, n. 6, p. 639-662, ago. 2004.

BARBIERI, J. C. et al. Inovação e sustentabilidade: novos modelos e proposições. Revista de Administração de Empresas - RAE, São Paulo, v. 50, n. 2, p. 146-154, abril-junho, 2010.
BARDIN, L. Análise de conteúdo. Tradução de L. A. Reto e A. Pinheiro. Lisboa: Edições 70, 2002.

CARVALHO, C. A.; VIEIRA, M. M. F.; GOULART, S. A trajetória conservadora da teoria institucional. Revista Brasileira de Administração Pública - RAP, Rio de Janeiro, v. 39, n. 4, p. 849-874, 2005.

DAROIT, D.; NASCIMENTO, L. F. Dimensões da inovação sob o paradigma do desenvolvimento sustentável. In: ENANPAD, 28, 2004, Paraná. Anais... Paraná: ANPAD, 2004.

DIMAGGIO, P. J.; POWELL, W. W. A gaiola de ferro revisitada: isomorfismo institucional e racionalidade coletiva nos campos organizacionais. Revista de

Administração de Empresas - RAE, São Paulo, v. 45, n. 2, p. 74-89, 2005.

ELKINGTON, J. Canibais com garfo e faca. São Paulo: Makron Books, 2001.

ENRÍQUEZ, M. A. R. da S. Mineração e desenvolvimento sustentável - é possível conciliar? Revista

Iberoamericana de Economía Ecológica, Barcelona, v. 12, p.51-66, 2009.

ENRÍQUEZ, M. A. R. da S.; DRUMMOND, J. Socialenvironmental certification: sustainable development and competitiveness in the mineral industry of the Brazilian Amazon. Natural Resources Forum, Estados Unidos, v. 31, p. 71-86, 2007.

HILSON, G., MURCK, B. Sustainable development in the mining industry: clarifying the corporate perspective.

Resources Policy, Estados Unidos, v. 26, n. 4, p. 227 238, 2000.

INTERNATIONAL Council on Mining and Metals (ICMM). 2008. 10 Princípios para o desempenho no campo do desenvolvimento sustentável. [2010]. Disponível em: <http://www.icmm.com/document/1323>. Acesso em: 10 dez. 2010.

INTERNATIONAL Council on Mining and Metals (ICMM). 2010. Sobre o ICMM. Disponível em: <http://www. icmm.com/portuguese > . Acesso em: 20 nov. 2010. 
MEYER, J. W.; ROWAN, B. Institutionalized organizations: formal structures as myth and ceremony. American

Journal of Sociology, Chicago, v. 83, n. 2, p. 340-363, 1977.

PARK, Jacob. China, business and sustainability: understanding the strategic convergence. Management Research News, United Kingdom, v. 31, n. 12, p. 951958, 2008.

SABEDOT, S. Tecnologia e sustentabilidade na indústria mineral. Diálogo, Canoas, v. 6, p. 15-34, 2005.

SAVITZ, S. A empresa sustentável. Rio de Janeiro: Elsevier, 2007.

SELZNICK, P. A liderança na administração: uma interpretação sociológica. Rio de Janeiro: FGV, 1972.

SOLOMON, F.; KATZ, E.; LOVEL, R. Social dimensions of mining: research, policy and practice challenges for the minerals industry in Australia. Resources Policy, Estados Unidos, v. 33, 2008, p. 142-149.

VIANA, M. B. Licenciamento ambiental em minerações de Minas Gerais: novas abordagens de gestão. 2007. 305 p. Dissertação (Mestrado em Desenvolvimento Sustentável) - Universidade de Brasília, Brasília, 2007. 